wheelbarrow. I am not inclined to provide myself with a hundredweight of books, although these are available at the local hospital. I am even less inclined to believe that a single textbook weighing only half a stone could ever cover all my needs. It has been tried several times by intelligent, diligent people and I reviewed two of them with words to the effect that this was a gallant effort to achieve the impossible.

Dr David Brooks (24 February, p 553) makes the important point that problems look different in general practice. Perhaps we need an agreed basic hundredweight of textbooks readily available to all doctors, with one loan copy and one reference copy in each local hospital or health centre. There might also be a separate series of "Variations in Your Branch." The largest "variation volume" would be for GPs but even this could be quite slim. Acute appendicitis, for instance, looks much the same at home as it looks in the casualty department, although the diagnosis may have become more or less obvious during the couple of hours between the one and the other.

Maldon, Essex

David Cargill

\section{Priorities in road accidents}

SIR,-In your leading article (3 February, $p$ 287) you discussed priorities in road accident prevention. I should like to suggest four priority measures which are likely to reduce accidents in some high risk groups.

In 19775272 children were killed or seriously injured, with the highest proportion in the 5-9 age group. ${ }^{1}$ Two-thirds of child casualties occurred in residential districts on $\mathrm{C}$ or unclassified roads. In $30 \%$ of these incidents children ran into the road from behind stationary vehicles. Prohibition of parking in residential districts from 8 am to $7 \mathrm{pm}$ (when $95 \%$ of these accidents occur) should reduce casualty rates in children.

Only $37 \%$ of schools teach road safety. ${ }^{2}$ The decision lies with the local education authorities and individual schools. Child casualty figures are so appalling that the Minister of Education should direct all education authorities to include road safety in the curriculum of teachers' colleges and schools. Children should be taught in the classroom as well as at the roadside.

In $1977 \quad 19338$ riders of two-wheeled motor vehicles were killed or seriously injured. Motorcyclists can be a menace on the roads: in $78 \%$ of collisions car occupants, pedal cyclists, or pedestrians were injured. ${ }^{3}$ The young and inexperienced are involved in a high proportion of accidents. At present fewer than $10 \%$ of learner riders attend training courses. The introduction of a statutory training period, before being allowed on the road, is long overdue.

In about $30 \%$ of vehicle collisions the side of the car is hit, and its occupants may be seriously injured if the passenger compartment is deformed. Seat belts are effective in frontal but not in side crashes. Doors should therefore be designed to absorb the impact; this can be achieved by stronger hinges and locks and particularly by reinforcing them. In the United States a statutory safety standard directs that car doors must be strong enough to withstand a specified impact. The introduction of such a regulation in this country would not only reduce injuries but also help the export drive. Department of Thoracic Surgery,
Poole Hospital, EUGENE HOFFMAN Middlesbrough, Cleveland

1 Department of Transport, Road Accidents; Great

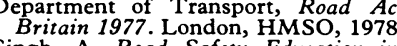
Singh, A, Road Safety Education in Primary and
Middle Schools, Supplementary Report 207UC. Crowthorne, TRRL, 1976.

Whitaker, J, Motor Cycle Safety-Accident Survey and Rider Injuries, Supplementary Report 239. Crow-
thorne, TRRL, 1976.

\section{Motorcycle crash helmets}

SIR,-The comments made by Dr Richard Garratt (10 February, p 413) on freedom of choice in the wearing of motorcycle crash helmets raise a number of points that are a good deal more important than just the simple issue of compulsion.

The value of crash helmets in preventing serious head injuries is now proved beyond doubt, although certain design features could still be improved. Not only is there evidence to prove the value of this specific intervention measure but there is now sadly very convincing evidence from the USA to show the dire consequences of relaxing such measures. In the USA by the end of 1978 some 26 States had repealed mandatory crash helmet laws. ${ }^{1}$ In spite of assurances to the contrary, in most of these States helmet-wearing rates fell rapidly from over $95 \%$ to below $60 \%$. In the States for which data are available fatal head injuries in motorcyclists doubled soon after the repeal was introduced. For those motorcyclists not wearing crash helmets there were twice as many head injuries and three to nine times as many fatalities (figures vary from State to State) as in riders who were wearing helmets.

It is wrong for Dr Garratt to say that wearing or not wearing crash helmets affects no one but the rider. Notwithstanding the human tragedies affecting family and friends, the costs of treating and rehabilitating patients with head injuries are considerable. A small proportion never fully recover and require lifetime support from family and the State. The widespread usage of crash helmets has prevented many of these tragedies but sometimes the force of the impact is so severe that no amount of protection is going to prevent serious injury. Our already unacceptably long waiting lists would be even further extended were crash helmet laws to be repealed.

In view of the very serious nature and high numbers of motorcycle accidents (in 1976 in Britain motorcycles accounted for $20 \%$ of all casualties in road traffic accidents yet they accounted for only about $2.3 \%$ of the total motorised milage ${ }^{2}$ ) there is even a case for still further legislation. No other methods have yet been shown to be effective in significantly reducing the carnage. There is particularly a need to pay attention to the teenage males who account for half of all motorcycle casualties (in 1975) ( $^{3}$ and among whom (in 1975) $43.3 \%$ of all deaths result from road traffic accidents. Young adult men are also very much at risk, especially in cars. Both of these groups are also responsible for involving many other innocent people such as passengers or other road users in many accidents.

The use of dipped headlights, bright clothing, and bright helmets ("Bright Gear Rules, OK") make the motorcyclist far more conspicuous and have been proved in parts of the USA to reduce accidents by as much as half. Since efforts at voluntary compliance have had only limited success in Britain the next logical step is legislation. The argument for compulsory training and testing before being allowed on the road is, so far, less convincing, although if pilot licensing principles were applied (would they be so impracticable?) we could confidently expect to see higher standards of riding and safety. We still do not have a planned programme of road safety teaching in many of our schools so how can we expect any more specialised training to succeed at a later date ? Since jumping on to a motorcycle is the greatest threat to the life and health of a teenager it surely behoves us to do as much as we can to reduce the risks. Public health ordinances were enacted for certain diseases on evidence of far less risk than this.

Finally, if the anti-compulsion lobby really wish to press their case it is as well to point out that nobody obliges them to ride a motorcycle on the public roads. That is where the personal choice lies. Having once decided to ride a motorcycle it is not unreasonable to require the rider to comply with a law which has been introduced very much in the interests of themselves and of society generally.

Much as one sympathises with the "freedom of choice" point of view this is such a serious community health problem that one would hope that good sense will prevail. The majority accept crash helmet legislation as being reasonable and sensible. Let us keep it that way.

Warwickshire AHA, South District,

J G AvERY

Leamington Spa

US Department of Transportation. News Release, NHTSA 3-79 Washington DC, 1979.

Accidenty for the Prevention of Accidents. Road 1978.

Department of Transport. Road Accider
Britain 1975. London, HMSO, 1977.

\section{Fatal accidents on non-gritted roads}

SIR,-Dr P J Tomlin's letter about fatal accidents on ungritted roads (24 February, p 547) does an injustice to the Health and Safety Executive as he is accusing it of ignoring a situation outside its terms of reference.

The HSE is empowered by the Health and Safety at Work Act and the Factories Act to inspect the work premises and processes, and the people employed in them, to ensure that all is well. The Factory Inspectorate and Employment Medical Advisory Service carry out these functions. The conditions of roads and accidents which occur on them are covered by bylaws and the Road Traffic Acts, and as such are the responsibility of the local authorities, the police, and fire and ambulance services.

His point about the results of non-gritting are taken. One hopes that similar letters about results of action by the medical profession never need to be written.

S H M LogaN

Altrincham, Cheshire

\section{Driving after anaesthetics}

SIR,-In the third edition of Medical Aspects of Fitness to Drive1 Dr J D J Havard, principal deputy secretary, BMA, writes, "With most 
general anaesthetics, it is safer to advise against driving for 48 hours afterwards." The apparent divergence of this advice from usual practice in Britain, coupled with the eminence of the author, has occasioned several queries from anaesthetists and the matter has come before the Anaesthetists' Subcommittee of the CCHMS and the Council of the Association of Anaesthetists.

The time taken to achieve safe "roadworthiness" varies widely between different anaesthetic agents and depends on dose, the metabolic fate of the agent, and the individual patient. It would be very rare for an interval of 48 hours to be necessary. There is no interval that could be unconditionally recommended for all situations; nevertheless, an interval of 24 hours or "a night's sleep" would normally be regarded as sufficient. Dr Havard's opinion must be presumed to be a personal one.

P BASKETT Honorary Secretary, Asociation of Anaesthetists of

$M$ VICKERS

Chairman, Anaesthetists' Subcommittee

London WC1 Havard, J D J, in Medical Aspects of Fitness to Drive,
ed A Raffle, 3rd edn, p 43. London, Medical Commission on Accident Prevention, 1976.

** We sent a copy of this letter to Dr Havard, whose reply is printed below.-ED, $B M \mathcal{F}$.

SIR,-This is the first time that this advice has attracted comment since it was first published in the second edition of the booklet in 1971. It is therefore most encouraging that clinicians, and in particular a body with the authority of the Association of Anaesthetists, are now taking an interest in this important issue.

The advice is prefaced by reference to the fact that tissue concentrations of anaesthetic drugs or of their metabolites can be identified in many cases up to 48 hours or more after administration. The problem has always been to determine the extent to which these trace elements impair the ability to drive properly. For reasons which are explained in the booklet, it has not been possible to carry out adequate studies on the relation between the concentration of such drugs and the risk of accident involvement as was done with ethyl alcohol. Thus we have to rely on laboratory studies of various tests of function and of skills resembling driving. Very few of these studies are reported in the clinical journals.

The most recent review of these studies was published a few weeks ago. ${ }^{1}$ Having referred to the paucity of epidemiological evidence, it concludes that "after general anaesthesia patients should refrain from driving for at least 10 hours and in some instances for 48 hours, depending on the length of the procedure and the agents employed." This advice is accompanied by a strict injunction to avoid other drugs and in particular alcohol.

The booklet is not aimed at specialists giving advice in their own field so much as at doctors generally. Anaesthetists are quite capable of deciding for themselves what advice they will give their patients, having regard to all the circumstances. However, not all anaesthetists make the necessary assumption that patients over the age of 17 will drive until proved otherwise. Other doctors, and in particular general practitioners, may be asked for advice by their patients following outpatient procedures, and I continue to believe that the advice given in the booklet is safest. Moreover, it is a criminal offence in this country to drive while the ability to drive properly is impaired for the time being by a drug, and in the event of an accident occurring the medical advice which was given (or not given) to the patient following an anaesthetic may assume unexpected importance. Those with experience of appearing as an expert witness under our accusatorial system of justice will appreciate the possible consequences, having regard to the uncertain state of the evidence on this important issue.

Meanwhile, it is prudent for doctors to err on the side of caution until some authoritative body such as the Association of Anaesthetists feels able formally to issue advice on usual practice.

JOHN HAVARD

British Medical Association,

London WCI

${ }^{1}$ Organisation for Economic Co-operation and Development Research Group S9, New Research on the Role of Alcohol and Drugs in Road Accidents.
p 63. Paris, OECD (available through HMSO),
1978. 1978 .

\section{Effect of once-daily atenolol on} ambulatory blood pressure

SIR,-The problem with short communications is the restriction to 600 words, one illustration, and five references. Under these conditions it is impossible to make full and detailed comparisons with the findings of other workers. We are fully aware of the important contributions of $\mathrm{Dr} M S$ Knapp and his colleagues (17 February, p 490), but the constraints of space were such that we could do no more than report the kernel of our own findings. The great advantages of the direct over the indirect methods of blood pressure measurement are increased accuracy and sensitivity and decreased disturbance of the subject. These factors could easily account for the differences in our results.

The cardiac department at Northwick Park Hospital owes a great deal to Professor Peter Sleight (17 February, p 491) for his help and encouragement in setting up the system for continuous blood pressure monitoring. It is therefore a cause of dismay to us that our publications on this subject are greeted by him with extensive criticism ${ }^{1}$ - criticism to which we feel we have responded adequately in the past. "Control" as defined by us was achieved to the satisfaction of the clinician armed with a stethoscope and sphygmomanometer. Quite clearly, we could not know what the intraarterial pressure was at this time until we actually measured it. The fact that the continuous intra-arterial measurements differed from the indirect measurement is hardly surprising. Furthermore, we agree with Professor Sleight that the lack of effect in the early morning has little to do with the duration of action of atenolol, as we stated in our paper.

Time of awakening is clearly important in the interpretation of 24-hour curves, but most adults have a habit of awakening at roughly the same time-no doubt as a result of conditioning over many years of working life.
We have adjusted our curves to normalise for this factor in both treated and untreated groups of patients and they remain substantially the same. Indeed, at least for untreated subjects our results are essentially similar to those of Professor Sleight and Professor W A Littler, who have been present at scientific meetings where this problem has been fully analysed and discussed. ${ }^{2-4}$ As for "blind interpretation of statistics," we would agree that statistical analysis of ambulatory blood pressure is a difficult subject, but had we failed to apply conventional methods of statistical analysis we could have been accused of deliberate bias. Two identical lines hardly need statistics to prove their identity. We cannot accept that technical problems such as damping are responsible for the differences in our results. Damping is not a problem with the perfusion units in use at Northwick Park and, since all the units in use worldwide are manufactured and tested here, we can claim some expertise. ${ }^{5}$ We have now performed 424 studies, 82 of which have been restudies on patients taking beta-blocking drugs (oxprenolol, metoprolol, pindolol, sotalol, propranolol, atenolol) in a variety of formulations. The results of all these studies have been qualitatively similar to the reported study with atenolol; the significance of quantitative differences is still under investigation.

We would disagree with both Professor Sleight and Professor Littler on the importance of physical activity in modifying 24-hour curves as analysed in this way, but would prefer to leave this to be the subject of a future communication. We do feel that the greatest single advantage of this ambulatory monitoring technique is that it allows observation of the patient in his own environment without the intrusion of medical personnel. Regulation of physical activity in a hospital ward may partially control some physiological variables but invalidates the attempt to monitor normal life.

We are left with an unsolved difference in results between our study and those of Professors Sleight and Littler. Examination of their results (Professor Sleight kindly sent us a copy of the 24-hour curves on his subjects) suggests that we were studying two different groups of patients. The mean ambulant diastolic pressure in both the Oxford and the Birmingham groups was less than $95 \mathrm{~mm} \mathrm{Hg}$ before treatment, whereas in our own group of patients it was $120 \mathrm{~mm} \mathrm{Hg}$. It is conceivable that beta-blocking drugs have different effects on mild and more severe hypertensive subjects. Much could have been gained if our suggestion of collaboration over these two small studies had been taken up; acrimonious debate on the minutiae of technique is not likely to be very productive.

E B RAFTERY

S MANN

M Millar-Craig

V BALASUBRAMANIAN

Northwick Park and Clinical Research Centre,

Harrow, Middx

Floras, J S, et al, Clinical Science and Molecular Medicine, 1978, 55, 395S.

Raftery, E B, and Millar-Craig, M, in Proceedings of an International Workshop on Blood Pressure Variation, 1978. University of Ghent (in press)

Mann, S, et al, Clinical Science and Molecular Medicine,

1ann, S, et al, in Proceedings of the VIIIth World Congress of Cardiology, $\mathrm{p} 1101$. Tokyo, 1978. Millar-Craig, M W, et al, Medical and Biological Engineering and Computing, 1978, 16, 727. 